\title{
Role of radiological investigations in the management of complicated otitis media
}

\begin{abstract}
Complications of otitis media are still a major problem in developing countries. The anatomical proximity of the middle ear cleft and mastoid air cells to the extracranial and intracranial compartments places structures located in these areas at a high risk of developing infectious complications. The incidence of chronic suppurative otitis media related complications has significantly reduced since the introduction of antibiotics, but this problem has not been completely eliminated. Radiological investigations play an important role in early diagnosis and management. In the present article radiological images of complicated otitis media is presented.
\end{abstract}

Keywords: complicated otitis media, radiology, investigations
Volume 10 Issue 5 - 2018

\section{Borlingegowda Viswanatha, Maliyappanahalli Siddappa Vijayashree \\ Otorhinolaryngology department, Bangalore medical college \&} research institute, India

Correspondence: Borlingegowda Viswanatha, FRCS (Glasgow), Professor of ENT, Bangalore medical college \& research institute, Bangalore, India, Tel 919845942832,

Email drbwiswanatha@yahoo.co.in

Received: May 15, 2018 | Published: October 26, 2018

\section{Introduction}

Chronic suppurative otitis media is the infection of the middle ear cleft and it is a common disease in the developing countries. Complications associated with it still poses a major problem in the developing countries. The anatomical proximity of the middle ear cleft and mastoid air cells to the extracranial and intracranial compartments places structures located in these areas at a high risk of developing infectious complications. Complications are usually seen more in the rural population than in urban population. The incidence of chronic suppurative otitis media related complications has significantly reduced since the introduction of antibiotics, but this problem has not been completely eliminated. The complications of chronic suppurative otitis media are still prevalent, particularly in developing countries and socioeconomically poor regions.

Chronic suppurative otitis media is broadly classified into mucosal and squamous types. The complications of chronic suppurative otitis media are divided into extracranial complications and intracranial complications. Complications are more common in patients having squamous type otitis media as compared to patients with mucosal type of otitis media. groups:

Complications of chronic otitis media are classified into two

\section{Extracranial complications:}
i. Subperiosteal mastoid abscess
ii. Mastoiditis
iii. Post aural fistula
iv. Facial nerve palsy
v. Labyrinthine fistula
vi. Petrositis
vii. Sensory neural hearing loss

\section{Intracranial complications:}

i. Cerebral abscess
ii. Cerebellar abscess
iii. Lateral sinus thrombosis
iv. Otitic hydrocephalus
v. Meningitis
vi. Subdural abscess
vii. Extradural abscess

The incidence complications of chronic suppurative otitis media and cholesteatoma have decreased with the introduction of newer antibiotics early in the twentieth century. These complications can be lethal if they are not diagnosed early and managed properly. With the continued development of multi-drug-resistant pathogens and immunocompromised diseases, these complications may again become more prevalent as our current antibiotics become less effective.

CT scan and MRI scans have become an inevitable part of the diagnostic algorithm in a patient with complicated chronic otitis media. It is considered as a life saving investigative technique for the same. It is non-invasive, rapid and also cost effective. It has the advantage of high resolution imaging, allowing early diagnosis of both intracranial and extracranial otological complications.

In the presence of clinical mastoiditis, a CT scan should be performed to evaluate for an unappreciated subperiosteal abscess or coalescent mastoiditis (Figure 1 \& Figure 2). MRI is also useful in mastoiditis cases (Figure-3), but it is not done routinely. CT scan can demonstrate subperiosteal abscess and possibly the cortical defect in the mastoid.

Because of the inability to accurately diagnose fistulae preoperatively on clinical grounds; imaging is likely an attempt to detect preoperatively, the exposed labyrinth, facial nerve, or dura, to aid in surgical planning. The ability to detect fistulae accurately on preoperative $\mathrm{CT}$ has been reported as $57 \%$ to $60 \%$.In a recent study by Viswanatha et al, it was detected only in $50 \%$ of cases. Although the debate regarding the need for preoperative imaging for cholesteatoma cases will continue, a research study by Viswanatha et al showed that $\mathrm{CT}$ scans are no more sensitive than history and physical examination 
in detecting labyrinthine fistulae. The definitive diagnosis of a fistula is only made intraoperatively, which reaffirms the need to approach all cholesteatoma cases with caution.

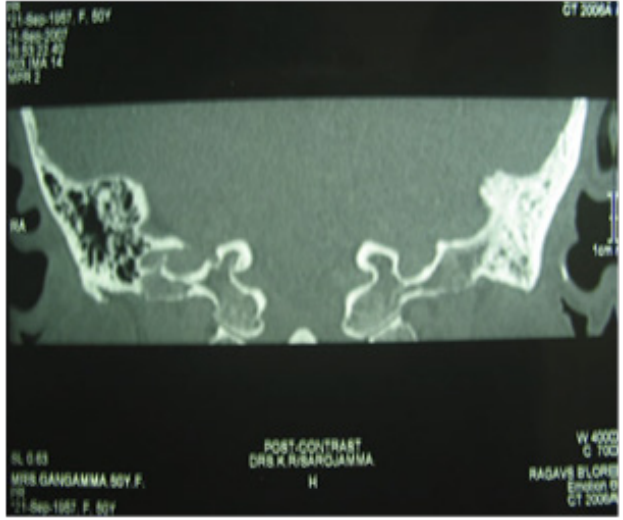

Figure I CT scan picture showing mastoiditis changes on the left side.

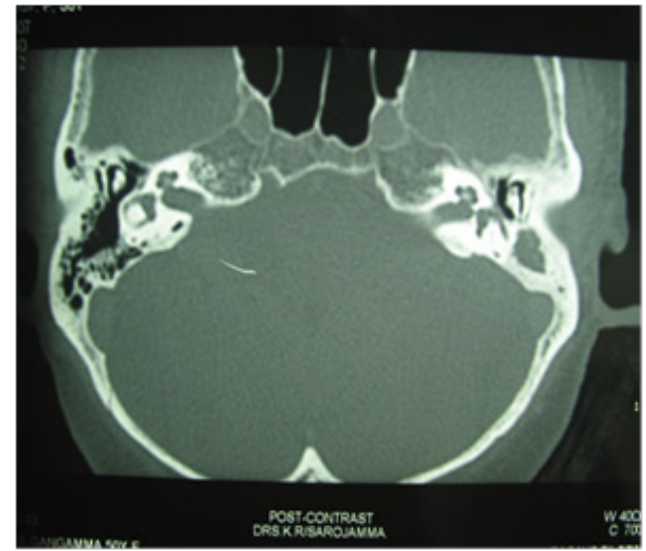

Figure $2 \mathrm{CT}$ scan picture of the temporal bone showing soft tissue mass in the mastoid cavity.

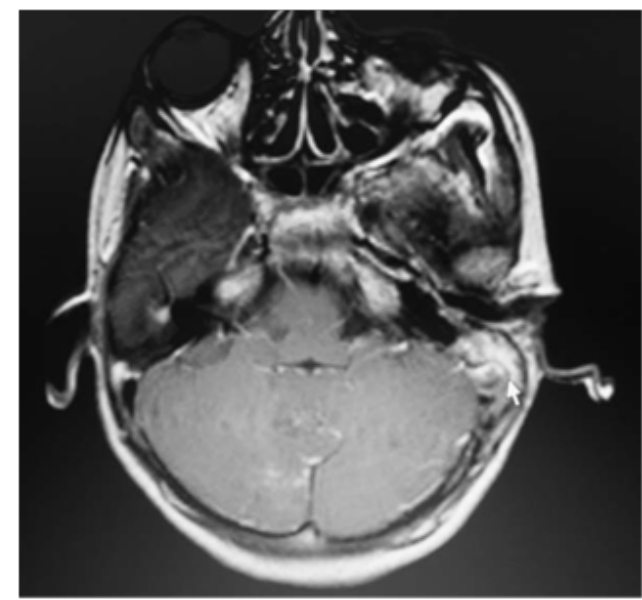

Figure 3 MRI showing (arrow) mucosal thickening in the left mastoid air cells.

Although a CT scan is not required for patients with facial palsy, it can be useful in therapeutic planning. When cholesteatoma involves the Fallopian canal, it may also erode structures such as the labyrinth or tegmen. When petrous apicitis is suspected, a CT scan should be performed to make the diagnosis and to evaluate surrounding anatomy. CT scan will also aid in the diagnosis of intracranial complications that often accompany this condition.MRI accurately shows the site and extent of the apical abscess (Figure 4).

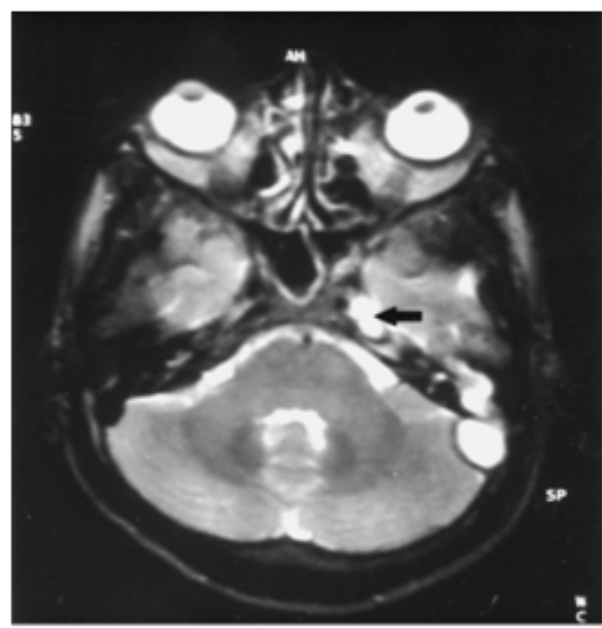

Figure $4 \mathrm{Axial} T 2$ weighted MRI showing hyper intense region (arrow) in the left petrous apex.

In cases of meningitis, a contrasted $\mathrm{CT}$ scan or MRI will show characteristic meningeal enhancement and rule out additional intracranial complications known to occur in up to $50 \%$ of these cases (Figure 5).

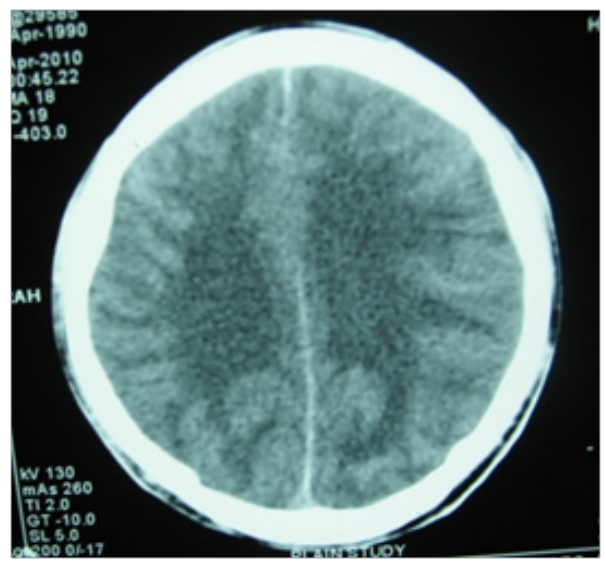

Figure $5 \mathrm{CT}$ scan with contrast showing meningeal enhancement.

In cases of brain abscesses, although the MRI gives better detail regarding the abscess itself, a CT scan gives valuable information about bony erosion of the mastoid, and can help in determining the cause of the abscess and the most appropriate treatment options (Figure 6-9).

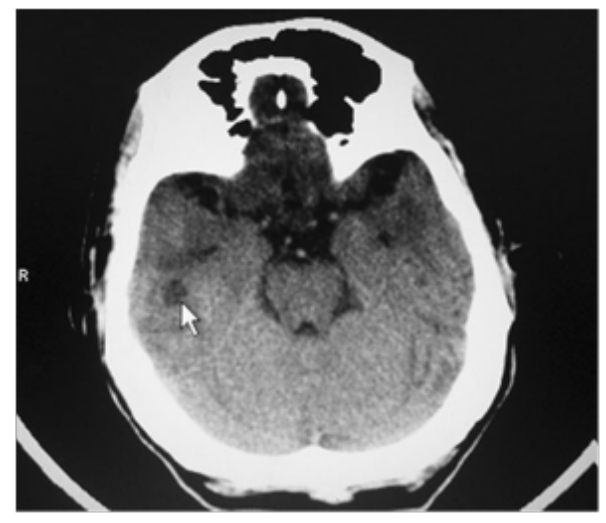

Figure $6 \mathrm{CT}$ scan of brain showing (arrow) hypodense lesion in the right temporal lobe. 


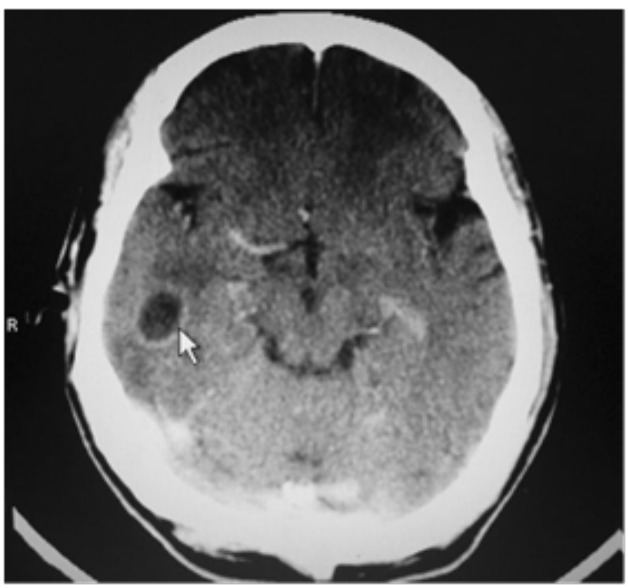

Figure $7 \mathrm{CT}$ scan with contrast showing (arrow) ring enhancing lesion in the right temporal lobe.

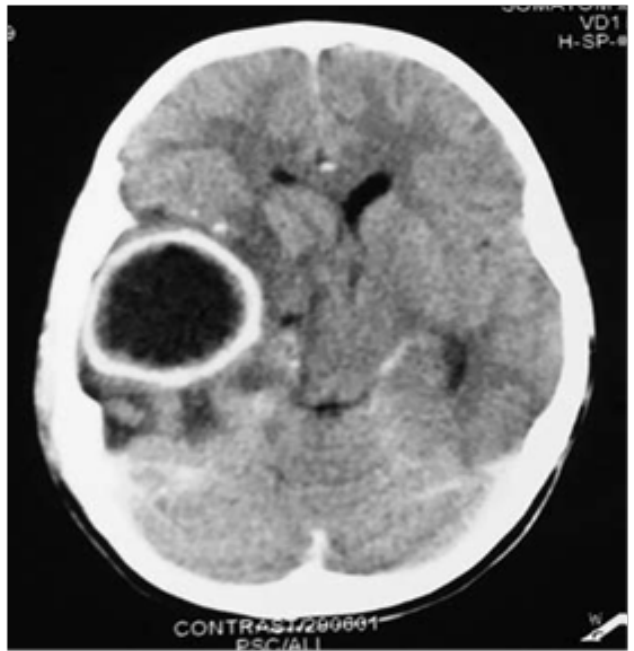

Figure $8 \mathrm{CT}$ scan with contrast showing ring enhancing lesion in the right temporal lobe.

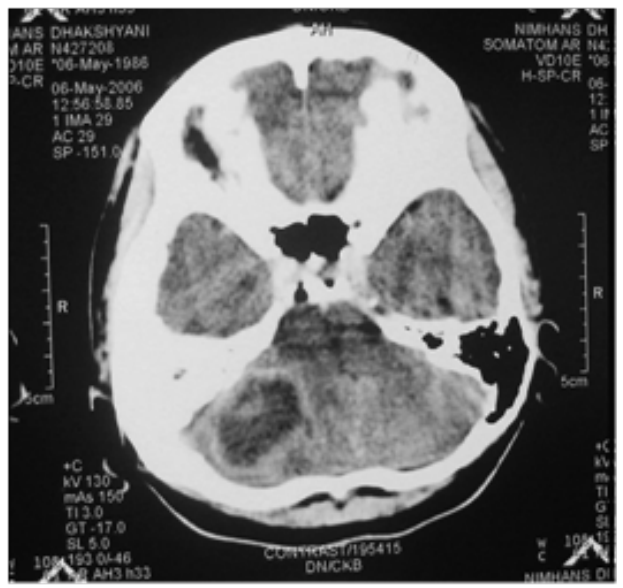

Figure 9 CT scan showing cerebellar abscess on the right side.

Imaging is required to rule out concomitant intracranial complications, or evidence of increased intracranial pressure. CT scan may show ventricular dilatation (Figure 10). In cases of otitic hydrocephalus, an MRI and magnetic resonance venogram should be performed to evaluate for ventricular enlargement, or coexisting intracranial complications, such as significant sinus thrombosis with obstruction. Magnetic resonance venogram will also confirm the presence of lateral sinus thrombosis, but is not required to make a diagnosis of otitic hydrocephalus.

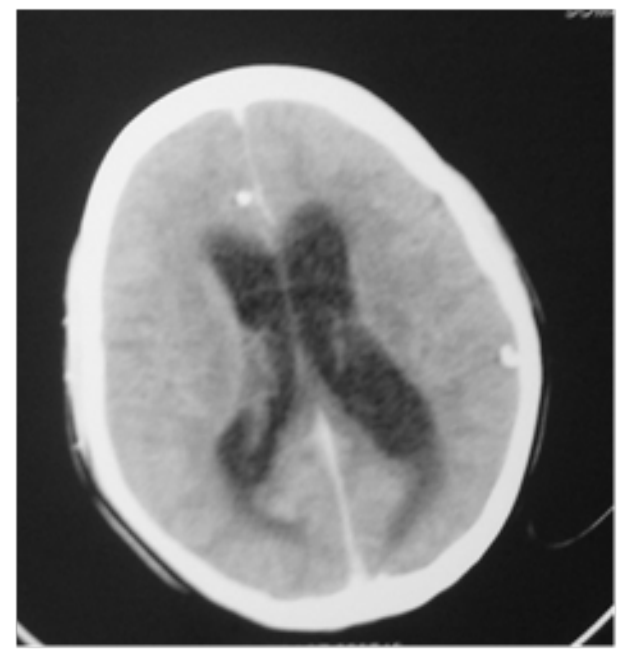

Figure $10 \mathrm{CT}$ scan showing dilated ventricles.

In lateral sinus thrombosis $\mathrm{CT}$ and MRI are the investigations of choice in making diagnosis. CT scan is useful in demonstrating the classic 'delta sign' of perisinus dural enhancement and filling defect of the lateral sinus (Figure 11) and also can help to rule out associated extracranial or intracranial complications. In study by Viswanatha et al, 'delta sign'was seen only in $50 \%$ of the cases.

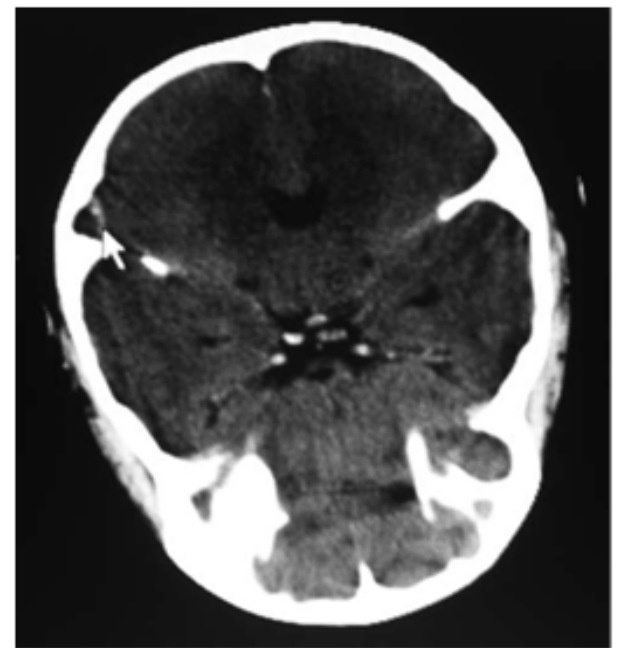

Figure II CT scan with contrast shows the delta sign (arrow) at the level of the lateral sinus.

MRI is more sensitive than CT in detecting the thrombus. MRI can show increased signal intensity of the thrombus and detect lateral sinus thrombosis not identified on a routine CT (Figure 12). It shows blood flow, sinus obstruction and subsequent reversal of flow.

On gadolinium-enhanced MRI, thrombus appears as soft tissue signal associated with vascular bright appearance of the dural wallthe "delta" sign as seen with gadolinium enhanced MRI (Figure 13).

MR venography, which can demonstrate the loss of signal and the absence of flow in the sinus, has proven to be more sensitive diagnostic tool in identifying the thrombus (Figure 14). 


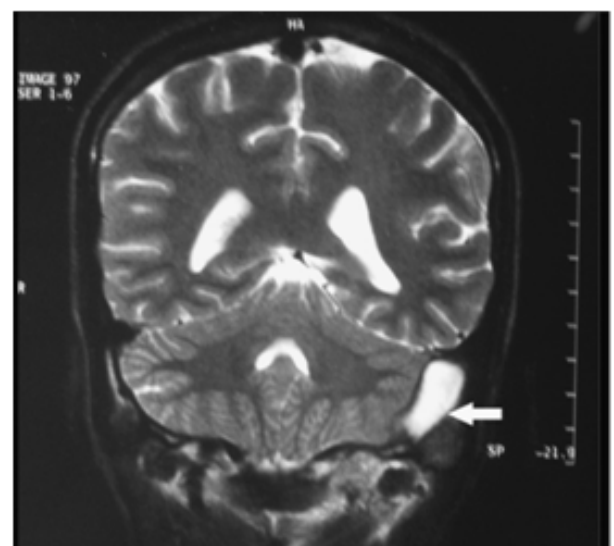

Figure I 2 MRI showing (arrow) occlusion and dilatation of left lateral sinus.

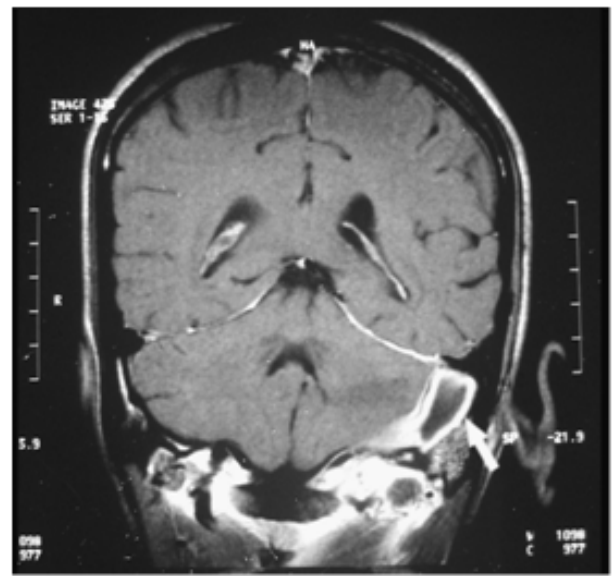

Figure I 3 MRI showing (arrow) post contrast enhancement of the sinus wall on the left side.

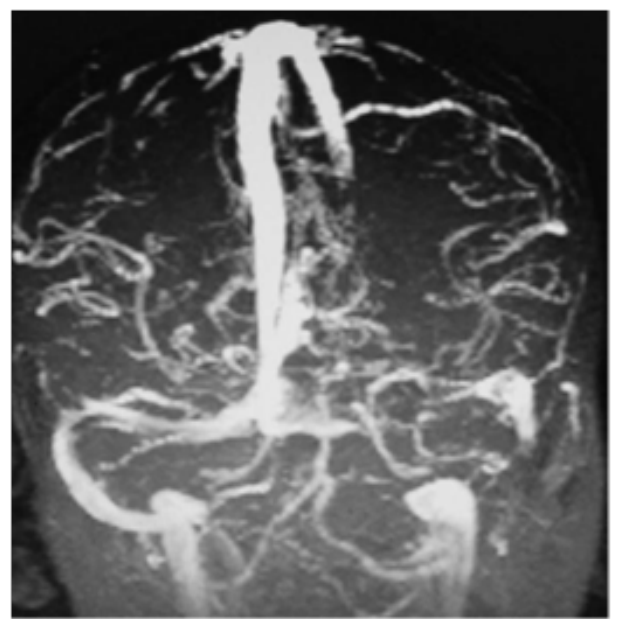

Figure I4 Magnetic resonance venography image demonstrating lack of flow in the left lateral sinus.

In lateral sinus thrombosis, MRI is the investigation of choice, and should be performed in conjunction with CT, there by fully evaluating associated otologic and cerebral pathology.

A contrasted CT scan or MRI is sufficient to diagnose extradural abscess and subdural abscess (Figure 15) (Figure 16). Even with a careful evaluation, this diagnosis is often made at the time of surgery.
The scutum, attic, oval window, and the round window niche represent middle ear structures that the radiologist is not able to assess reliably. Hence, these areas should be considered as weak, or of high risk for errors in the radiology report.

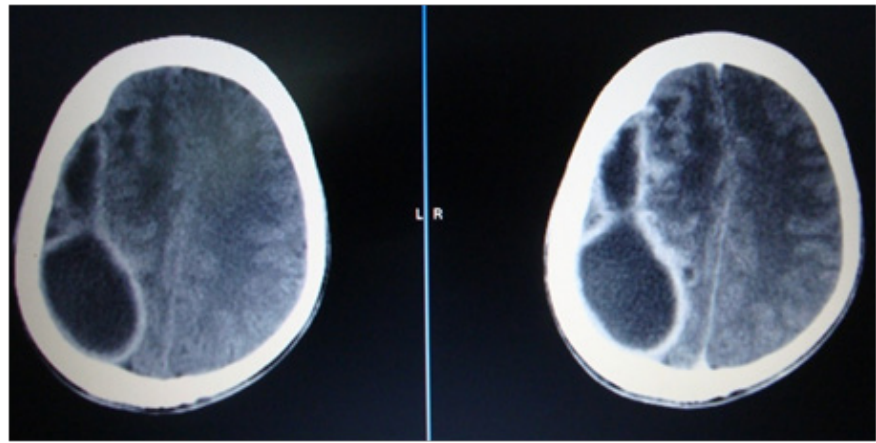

Figure I5 CT scan of brain with and without contrast showing extradural abscess.

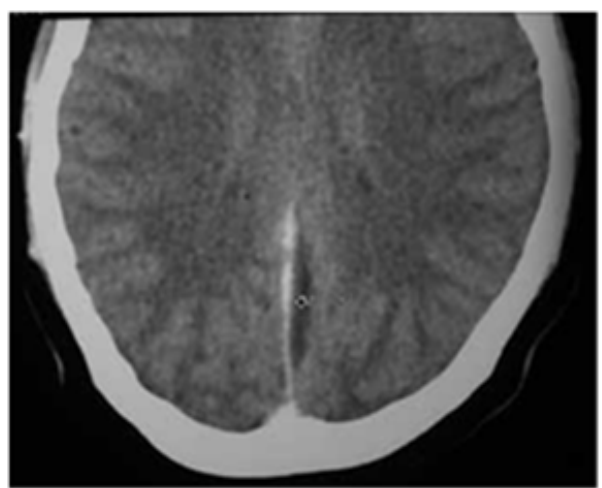

Figure 16 Contrast-enhanced CT shows the interhemispheric subdural abscess.

In developing countries taking repeat $\mathrm{CT}$ scans routinely after surgery is still financially challenging to most of the patients. This makes it necessary for the surgeon to know the situations during the postoperative period when a repeat $\mathrm{CT}$ scan is inevitable and should be asked for.

Radiological investigations are indicated in cases of cholesteatoma with complications and in cases of recurrent cholesteatoma. They cannot replace the clinical suspicion and judgement of the surgeon and these techniques should be judiciously done to supplement the clinical diagnosis. CT scans helps the surgeon in early diagnosis, planning and management of the disease. It also aids the surgeon in anticipating any difficulties that may arise during the surgical procedure. ${ }^{1-18}$

\section{Acknowledgements}

None.

\section{Conflict of interest}

The author declares no conflict of interest.

\section{References}

1. Smith JA, Danner CJ. Complications of chronic otitis media and cholesteatoma. Otolaryngol Clin North Am. 2006;39(6):1237-1255

2. Viswanatha B, Naseeruddin K. Complications of atticoantral otitis media -Revisited. Advances in Research. 2014:2(11);666-695. 
3. Vlastarakos PV, Kiprouli C, Pappas S, et al. CT scan versus surgery: how reliable is the preoperative radiological assessment in patients with chronic otitis media? Eur Arch Otorhinolaryngol. 2012:269:81-86.

4. Viswanatha B. Lateral sinus thrombosis in children. A review Ear Nose Throat J. 2011;90(6):E28-E33.

5. Viswanatha B, Kaja Naseeruddin K. Neurotologic complications of chronic otitis media with cholesteatoma. Journal of Neurology and Epidemiology. 2013;1:20-30

6. Viswanatha B. Lateral sinus thrombosis: A major problem still with us. Indian journal of Otolaryngology \& head and neck surgery. 2007;59(1):24-27.

7. Alzoubi FQ, Odat HA, Al-balas HA, et al. The role of preoperative CT scan in patients with chronic otitis media. Eur Arch Otorhinolaryngol. 2009;266(6):807-809.

8. Yildirim-Baylan M, Ozmen CA, Gun R, Yorgancilar E, et al. An evaluation of preoperative computed tomography on patients with chronic otitis media. Indian J Otolaryngol Head Neck Surg. 2012;64(1):67-70

9. Viswanatha B. Lateral sinus thrombosis with cranial nerves palsies. International Journal of Pediatric Otorhinolaryngology extra. 2007;2(3):165-168.

10. Viswanatha B. Otitic hydrocephalus: A report of 2 cases. Ear Nose Throat J. 2010;89(7):E34-37.
11. Pendio ND, Testa JRG, Inoue DP, et al. Presentation, treatment, and clinical course of otogenic lateral sinus thrombosis. Acta OtoLaryngologica. 2009;129:729-734.

12. Viswanatha B, Naseerudin K. Lateral sinus thrombosis in otology: A review. Mediterr J Hematol Infect Dis. 20107;2(3):e2010027.

13. Viswanatha B. Interhemispheric subdural abscess: A rare complication of attico antral ear disease. Ear nose \& throat journal. 2012;91(8):E26-28.

14. Kaplan DM, Kraus M, Puterman M, et al. Otogenic lateral sinus thrombosis in children. International Journal of Otorhinolaryngology. 1999;49(3):177-183.

15. Lee JH, Choi SJ, Park K, et al. Managements for lateral sinus thrombosis: does it need the ligation of internal jugular vein or anticoagulants?. Eur Arch Otorhinolaryngol. 2009;266(1):51-58.

16. Viswanatha B, Sarojamma, Vijayashree MS, et al. Unilateral attico antral disease with bilateral intracranial complications. Indian journal of Otolaryngology \& head and neck surgery. 2012;64(1):82-86.

17. Omer unal F, Sennaroglu L, Saatci I. Otitic hydrocephalus: Role of radiology for diagnosis. International journal of otorhinolaryngology 2005;69:897-901.

18. Viswanatha B, Naseeruddin K. Conservative management of otogenic brain abscess with surgical management of attico antral ear disease: A Review. Indian Journal of Otolaryngology and Head \& Neck Surgery. 2012;64(2):113-111. 